\title{
Impact of Nipple Shield Use on Milk Transfer and Maternal Nipple Pain
}

AU1 Viviane Silva Coentro, ${ }^{1}$ S. Lisa Perrella, ${ }^{1}$ Ching Tat Lai, ${ }^{1}$ Alethea Rea, ${ }^{2}$ Kevin Murray, ${ }^{3}$ and D. Tracy Geddes ${ }^{1}$

\begin{abstract}
Background: Nipple pain is a common cause of early cessation of breastfeeding. A nipple shield (shield) is often used to improve breastfeeding comfort. There are concerns that shield use may limit milk transfer. The aims of this study were to determine whether shield use reduces milk transfer and maternal nipple pain.

Methods: A within-subject study of two groups of breastfeeding dyads (infants $<6$ months) was conducted; Control Group (CG): no breastfeeding difficulties; Pain Group (PG) shield used for nipple pain. There were two monitored sessions where shield use was randomized. Test weights and pain questionnaires were completed, and percentage of available milk removed (PAMR) was calculated.

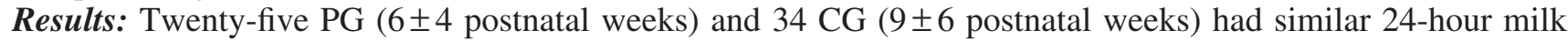
production (PG: $676 \pm 239 \mathrm{~mL}$, CG: $775 \pm 162 \mathrm{~mL}, p=0.083$ ). PG mean milk transfer volume and PAMR did not differ with shield use (no shield: $46 \mathrm{~mL}, 59 \%$; shield: $40 \mathrm{~mL}, 53 \%$, volume $p=0.38$, PAMR $p=0.64$ ). CG mean volume and PAMR were reduced with shield use (no shield: $65 \mathrm{~mL}, 64 \%$; shield: $31 \mathrm{~mL}$, 33\%, volume $p<0.001$, PAMR $p<0.001$ ). PG pain scores were similar with and without shield use (Visual Analog Scale $p=0.44$, McGill $p=0.97$ ).
\end{abstract}

Conclusions: Shield use did not impact either milk production or milk transfer in breastfeeding women experiencing nipple pain.

Keywords: nipple shield, nipple pain, breastfeeding, milk transfer

\section{Introduction}

$\mathbf{T}$ HE World Health Organization recommends exclusive breastfeeding for infants up to 6 months of age, with continued breastfeeding up to 2 years of age or beyond. ${ }^{1,2}$ Many women cease breastfeeding earlier than they had planned due to nipple pain. ${ }^{3}$ When strategies to reduce nipple pain are uneffective, an ultrathin silicone shield may be used as an aid to manage nipple pain. The shield is placed over the nipple and areola, providing a physical barrier to protect sore nipples and enable continuation of breastfeeding. Reported maternal experiences of shield use indicate that they are perceived to be helpful in initiating breastfeeding and preventing early breastfeeding termination. ${ }^{4}$

Commercially available shield sizes vary to accommodate different nipple sizes. Clinicians are concerned that shield use reduces milk transfer, and there is some evidence that shield use negatively impacts breastfeeding exclusivity and dura- tion. ${ }^{5,6}$ Previous research findings suggest that the use of rubber "Mexican Hat" and latex shields when pumping or breastfeeding reduces milk transfer volumes. ${ }^{7,8}$ However, there are several methodological issues related to study design that raise concerns regarding validity of the reported findings, such as not accounting for differing degrees of breast fullness caused by consecutive breastfeeding and/or pumping with and without a shield. In preterm breastfeeding dyads, shield use has been shown to facilitate milk transfer. The mean duration of shield use (33 days, coinciding with term corrected age) did not reduce the mean breastfeeding duration of 169 days, which exceeded that of their low-risk term counterparts.?

Careful interpretation of previous study findings is needed as milk transfer volume is not a reliable indicator of milk removal. That is, the volume of milk available in the breast varies throughout the day and so may differ depending on the degree of breast fullness at the start of pumping or

\footnotetext{
${ }^{1}$ Faculty of Science, School of Molecular Sciences, The University of Western Australia, Crawley, Australia.

${ }^{2}$ Mathematics and Statistics, Murdoch University, Murdoch, Australia.

${ }^{3}$ Faculty of Health and Medical Sciences, Population and Global Health, School of Population and Global Health, The University of Western Australia, Crawley, Australia.
} 
breastfeeding. Use of a validated measure of breast fullness and expression of the transferred volume as a percentage of available milk removed (PAMR) ${ }^{10,11}$ provide a more accurate measure that can be used to evaluate the effect of shield use on milk removal.

The aims of this study were to investigate the effect of shield use on milk transfer, maternal nipple pain, and breastfeeding duration to 20 weeks in breastfeeding dyads with maternal nipple pain.

\section{AU2 Materials and Methods}

\section{Participants}

Breastfeeding dyads (1-6 months) were recruited through international board certified lactation consultants (IBCLC) and the community between July 2016 and June 2019. Two groups were recruited: a Pain Group (PG) breastfeeding mothers using an ultrathin silicone shield to manage nipple pain; Control Group (CG) mothers with no breastfeeding difficulties. Inclusion criteria: birth at term (i.e., $\geq 37$ completed weeks gestation) and predominant breastfeeding (i.e. feeding $\leq 1$ bottle of formula/day). PG: mothers regularly used a shield ( $\leq 2$ breastfeeds/ 24 hours without shield) at the time of recruitment. Exclusion criteria: diagnosed cause of nipple pain, previous breast surgery, nipple piercing, $<18$ years of age, unable to speak and read English without assistance, infant oral anomaly/surgery, or diagnosed health condition.

The study was approved by the Human Research Ethics Committees of the Women and Newborn Health Service (2016124) and The University of Western Australia (RA/4/1/ 7863). Mothers provided written informed consent before participation.

\section{Study design}

A within-subject study was conducted in a laboratory situated at King Edward Memorial Hospital, Perth. Participants attended two monitored sessions where they were randomized to breastfeed with/without a shield, with the alternate condition used at the subsequent session. The same breast was offered at both sessions; PG breastfed from the most painful breast, while CG was randomized to feed from the left or right breast. Mothers completed background and pain questionnaires and were followed up by telephone up to 20 weeks postnatal.

For shield sessions, prefeed nipple base diameters were measured using a caliper (CE Analogic Caliper, Anhui, China), ${ }^{12}$ and mothers were fitted with a shield diameter $\geq 4 \mathrm{~mm}$ than the nipple base diameter. Available shield sizes were 16, 20, and $24 \mathrm{~mm}$ (Medela Contact Nipple Shield; Medela AG, Baar, Switzerland) and 18 and $28 \mathrm{~mm}$ (Mamivac Conical Nipple Shield; KaWeCo GmbH, Ditzingen, Germany). A new shield was centrally positioned over the mother's nipple by an IBCLC qualified researcher.

At each session, milk intake was measured by test weighing ${ }^{13}$ using an electronic baby weigh scale (Medela AG; resolution $2 \mathrm{~g}$, accuracy $\pm 0.034 \%$ ). Pre/post feed milk samples $(<1.0 \mathrm{~mL})$ were analyzed for cream content using the Crematocrit method. ${ }^{10,11}$ Mothers completed the Visual Analog Scale (VAS) ${ }^{14,15}$ and McGill Pain Questionnaire ${ }^{16}$ to assess nipple pain before and after each monitored breast- feed. Feeding efficiency $(\mathrm{mL} / \mathrm{min})$ was calculated as the total milk intake volume per total feed duration (minute) in each session.

Twenty-four hour milk production measurements were completed in mothers' homes within 7 days of the study sessions using electronic scales sensitive to $2 \mathrm{~g}$ (Medela BabyWeigh Scales; Medela AG). Infants were weighed pre and post breastfeeds and milk collection bottles weighed pre and post any pumping sessions over a 24 -hour period to determine milk production. ${ }^{17}$ These data are used to calcuate total 24-hour milk maternal production (sum of all breastfeeding and pumping volumes), infant milk intake at the breast (sum of all breastfeeding volumes), and infant total milk intake (sum of all breastfeeding and supplementary feed volumes). Furthermore, feeding characteristics such as breastfeeding frequency (feeds/24 hours) and duration of breastfeeds (minutes), pumping frequency, and volume for mothers that pump are described. Milk samples $(<1.0 \mathrm{~mL})$ were collected before and after every breastfeed and pumping session and frozen for later analysis. All breastfeeding and pumping measurements were expressed in grams and considered equivalent to milliliter $(1.03 \mathrm{~g} / \mathrm{mL}=1.0 \mathrm{~mL}$ of breast milk). ${ }^{18}$

PAMR was estimated ${ }^{19}$ allowing comparisons of degree of breast emptying between breastfeeding sessions and between groups.

Follow-up telephone calls were made at 12, 16, and 20 weeks postnatal. Mothers reported their infants' feeding method and frequency over the previous 24 hours, including exclusivity of breastfeeding, use of expressed breast milk or formula, shield use, pumping frequency and timing, and reasons for weaning from shield and/or breastfeeding.

\section{Sample size determination}

Sample size determination was completed using the data source of McClellan et al. ${ }^{20}$ where raw data were sourced from 21 mothers reporting nipple pain and compared with 21 mothers without nipple pain with regard to 24-hour milk production, milk transfer volumes, and estimated milk volume available in the breast. The sample size was calculated using a bootstrap approach where it considered two feeds and then added a shield effect in one of the feeds assuming that shield use decreases milk removal from the breast. Analyses were performed using $\mathrm{R}$, and a sample size of $n=30$ was recommended to detect an average significant difference of $20 \pm 5 \mathrm{~mL}$ (power: $0.83, \alpha: 0.05$ ) between sessions with and without shield use.

\section{Statistical methods}

Demographic data were analyzed using Chi squared tests or a Fisher's exact test (categorical variables) or $t$-test (continuous variables). Twenty-four hour milk production volumes were compared using unpaired $t$-test as were differences in volume, PAMR, feeding measures, and pain scores (with and without a shield) by group (CG and PG). Two linear mixed models were fitted, one with the response frequency of feeds and the second with frequency of expression feeds; both had the explanatory variables infant age (in weeks) and shield use (yes or no) with a random effect for infant.

Descriptive statistics is presented as frequencies and percentages for categorical variables and mean and standard 
IMPACT OF NIPPLE SHIELD USE ON MILK TRANSFER

deviation for continuous variables. The significance level was set at 0.05 , and all analyses were carried out in $\mathrm{R}$ version 3.6.2 (The R Foundation for Statistical Computing).

\section{Results}

Dyads (PG $n=32$, CG $n=49$ ) were recruited, with six of PG excluded from analysis due to study withdrawal $(n=1)$; diagnosis of ankyloglossia after recruitment $(n=3)$; infant refusal of intraoral vacuum tube $(n=1)$; and inability to breastfeed without a shield S $(n=1)$. For CG 14 dyads were excluded from analysis due to infant refusal of the shield $(n=8)$ and intraoral vacuum tube $(n=1)$; mother disclosed recent cessation of shield use $(n=1)$; infant too unsettled to breastfeed $(n=2)$; and study withdrawal $(n=1)$. Therefore, 25 PG dyads and 34 CG dyads completed the study. For PG nipple shield use commenced within a week of birth after nipple pain could not be resolved with assistance from a midwife to adjustment positioning and attachment. Most mothers reported that nipple shield use was instigated by a midwife during the hospital stay. For PG mothers, the typically used nipple shield size matched the fitted size in 21/25 (18 $\mathrm{mm} n=5,20 \mathrm{~mm} n=3,24 \mathrm{~mm} n=13)$. Of the four that didn't match, two were fitted with a smaller size $(24 \mathrm{~mm}$ used, $18 \mathrm{~mm}$ and $20 \mathrm{~mm}$ fitted) and two were fitted with a larger size $(16 \mathrm{~mm}$ used and $20 \mathrm{~mm}$ fitted, $24 \mathrm{~mm}$ used and $28 \mathrm{~mm}$ fitted). Demographic characteristics are presented in

T1 Table 1.

The PG mean milk transfer volume and PAMR did not

T2 differ with shield use (Table 2). For CG when a shield was used the mean volume and PAMR were $34 \mathrm{~mL}$ (95\% confidence interval $[\mathrm{CI}]-46.7$ to $-20.6, p<0.001)$ and $31 \%(95 \%$ CI -43.8 to $-18.3, p<0.001)$ lower than without shield use

F1 (Fig. 1). For both PG and CG the mean milk transfer rate was significantly higher for breastfeeds without a shield $(7 \pm 4 \mathrm{~mL} / \mathrm{min}$ and $12 \pm 11 \mathrm{~mL} / \mathrm{min}$, respectively) than with shield use $(4 \pm 3 \mathrm{~mL} / \mathrm{min}$ and $5 \pm 5 \mathrm{~mL} / \mathrm{min}$, respectively), (PG 95\% CI 0.87-3.85, $p=0.003$; CG 95\% CI 3.50-11.95, $p=0.001)$ (Table 2).
PG and CG mean 24-hour milk productions were within the reference range ${ }^{17}$ with no difference in 24 -hour productions $(p=0.13)$, mean breastfeeding frequency $(p=0.17)$, and PAMR for left and right breasts $(p=0.53, p=0.79$, respectively). The PG infants had longer breastfeeding durations than CG infants (left breast 95\% CI -8.44 to -2.04 , $p=0.002$; right breast $95 \% \mathrm{CI}-8.15$ to $-1.30, p=0.008$ ), but transferred less milk (95\% CI 114-317, $p<0.001)$ because PG mothers were expressing more frequently $(95 \% \mathrm{CI}-10.3$ to $-2.98, p=0.001$ ) (Table 3 ).

Eight PG mothers had low 24-hour milk production, that is, $<600 \mathrm{~mL} / 24$ hours $(485 \pm 108 \mathrm{~mL}, 284-590 \mathrm{~mL})$, of which seven mothers complemented with formula. There was no difference in pumping frequency between mothers with pain and low milk supply $(4.3 \pm 2.8)$ and those with pain and production within the reference range $(4.4 \pm 3.0, p=1.00)$. The total 24-hour volume pumped and breastfeeding frequency were not significantly different between $\mathrm{PG}$ and CG ( $p=0.15, p=0.17$, respectively) (Table 3 ).

The World Health Organization weight-for-age $z$-scores were similar between groups for infant birth weights, while that of the PG was lower at the time of the study sessions indicating a slower rate of weight gain (Table 1). One PG infant had an increase in $z$-score of $>0.67$ indicating an accelerated rate of weight gain, while four PG infants had a reduction in $z$-score of $<0.67$ indicating a sharp decline in infant growth. ${ }^{21}$ The impaired infant weight gain is likely due to inadequate total 24-hour milk volume intake (Table 3).

The PG mean VAS and McGill scores did not differ with shield use (VAS $p=0.44$, McGill $p=0.97$ ), and the scores indicated a moderate degree of pain during breastfeeding. McGill ratings in the sensory category with descriptors such as: shooting, sharp, stabbing, pinching, pulling, tingling, stinging, tender, and hurting were the most frequently selected descriptors by PG mothers both with and without the shield. As expected, CG pain scores indicated no pain during breastfeeding without a shield. CG mean McGill scores were significantly different when a shield was used, with sensory category descriptors such as: flickering, quivering, pinching,

Table 1. Maternal and Infant Characteristics

\begin{tabular}{lccc}
\hline Maternal characteristics & Pain group $(\mathrm{n}=25)$ & Control group $(\mathrm{n}=34)$ & p-Value \\
\hline Age (years) & $32 \pm 3^{\mathrm{a}}$ & $34 \pm 4$ & 0.05 \\
Intended breastfeeding duration (months) & $14 \pm 7^{\mathrm{a}}$ & $18 \pm 8$ & 0.05 \\
Primipara & $16(70)^{\mathrm{a}}$ & $15(44)$ & 0.10 \\
Highest level of education completed & $0(0)^{\mathrm{a}}$ & $3(9)$ & 0.11 \\
$\quad$ High school/professional registration & $23(92)^{\mathrm{a}}$ & $31(91)$ & \\
$\quad$ College/university or above & $39.1 \pm 1^{\mathrm{a}}$ & $40.0 \pm 1$ & 0.37 \\
Infant characteristics & $15(65)^{\mathrm{a}}$ & $23(68)$ & 1.00 \\
Birth gestation (weeks) & $3,538 \pm 363^{\mathrm{a}}$ & $3,535 \pm 449$ & 0.83 \\
Birth mode = vaginal & $0.4 \pm 0.9$ & $0.5 \pm 0.7$ & 0.87 \\
Birth weight (g) & $0.5 \pm 1.0$ & $0.1 \pm 0.8$ & 0.10 \\
WHO weight for age z-score at birth & $6 \pm 4^{\mathrm{a}}$ & $9 \pm 6$ & 0.004 \\
WHO weight for age z-score at study visit & $17(74)^{\mathrm{a}}$ & $21(64)^{\mathrm{b}}$ & 0.60 \\
Postnatal age (weeks) & & & \\
Dummy use = yes & & & \\
\hline
\end{tabular}

Results are reported as mean \pm SD for maternal age, intended breastfeed duration, birth gestational age, birth weight, WHO weight-forage $z$-scores, and postnatal age. Birth mode, parity, and dummy use are reported as number and percentage $(\%)$.

${ }^{\mathrm{a}}$ Missing data $n=2$

${ }^{\mathrm{b}}$ Missing data $n=1$.

SD, standard deviation; WHO, World Health Organization. 
Table 2. Milk Removal, Feeding Duration, Efficiency, and Pain Scores for Breastfeeds With and Without Shield

\begin{tabular}{|c|c|c|c|c|c|c|c|}
\hline \multirow[b]{2}{*}{ Variables } & \multicolumn{3}{|c|}{ Pain group $(\mathrm{n}=25)$} & \multicolumn{3}{|c|}{ Control group $(\mathrm{n}=34)$} & \multirow{2}{*}{$\begin{array}{c}\text { Comparison of differences } \\
\text { p-Value }\end{array}$} \\
\hline & No shield & Shield & p-Value & $\mathrm{p}$-Value & Shield & p-Value & \\
\hline Volume (mL) & $46 \pm 28$ & $40 \pm 25$ & 0.38 & $65 \pm 33$ & $31 \pm 22$ & $<0.001$ & 0.006 \\
\hline PAMR $(\%)$ & $59 \pm 31$ & $53 \pm 29^{a}$ & 0.64 & $64 \pm 22$ & $33 \pm 30$ & $<0.001$ & 0.03 \\
\hline Feed duration (minutes) & $9 \pm 6$ & $12 \pm 9$ & 0.14 & $7 \pm 5$ & $9 \pm 6$ & 0.20 & 0.46 \\
\hline Feeding efficiency (mL/min) & $7 \pm 4$ & $4 \pm 3$ & 0.003 & $12 \pm 11$ & $5 \pm 5$ & 0.001 & 0.03 \\
\hline VAS score & $4 \pm 3^{\mathrm{a}}$ & $4 \pm 3^{b}$ & 0.44 & $0.2 \pm 0.5$ & $0.2 \pm 0$ & 0.28 & 0.07 \\
\hline McGill score & $17 \pm 12$ & $16 \pm 14$ & 0.97 & $1 \pm 1^{\mathrm{a}}$ & $1 \pm 2^{a}$ & 0.02 & 0.22 \\
\hline
\end{tabular}

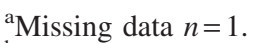

${ }^{\mathrm{b}}$ Missing data $n=2$. Results are reported as mean $\pm \mathrm{SD}$.

PAMR, percentage of available milk removed; SD, standard deviation;VAS, Visual Analog Scale.

pressing, tender, taut, and miscellaneous category descriptors such as: tight, drawing, and squeezing most commonly selected when using a shield for the first time $(-0.52,95 \% \mathrm{CI}$ -0.93 to $-0.10, p=0.02$ ) (Table 2).

Dyads were followed up by telephone with feeding methods T4 as reported in Table 4 . The proportions of infants fed any breast milk were similar between groups at 12 weeks $(p=0.16), 16$ weeks $(p=0.062)$, and 20 weeks $(p=0.065)$, respectively. Also there was no difference in the proportions of dyads exclusively breastfeeding at 20 weeks (46\% [6/13] PG, 67\% [18/ 26] CG; $p=0.68$ ). Three of the four PG mothers that weaned had lower intended breastfeeding durations (3 months, 6 months, 6 months, $n=1$ missing data) than PG (14 7 months) and CG (18 \pm 7 months) that were breastfeeding at 20 weeks.

Breastfeeding frequency was not associated with shield use $(p=0.35)$ but reduced with increasing infant age $(p=0.009)$, decreasing from nine feeds at 12 weeks and seven feeds at 16 and 20 weeks. Frequency of breast milk feeding (combined breast and expressed milk by bottle) was lower in PG compared to CG $(-2.46,95 \% \mathrm{CI}-4.20$ to -0.72 , $p=0.007)$ and differed by time point $(p<0.001)$ with feeding frequency at 16 weeks $(-1.64,95 \% \mathrm{CI}-2.37$ to -0.92 , $p<0.001)$ and 20 weeks $(-2.28,95 \%$ CI -3.05 to -1.50 , $p<0.001)$ lower than at 12 weeks. Pumping frequency was higher in PG compared to CG (11.75, 95\% CI 3.59-19.91, $p=0.006)$ and differed by each time point $(p=0.001)$. Pumping frequency at 16 weeks $(-5.23,95 \% \mathrm{CI}-9.91$ to $-0.54, p=0.03)$ and at 20 weeks $(-9.12,95 \% \mathrm{CI}-14.37$ to $-3.87, p=0.001)$ was lower than at 12 weeks.

Shield use reduced over time with $38 \%(8 / 21)$ of PG dyads stopping shield use before 12 weeks postnatal, $70 \%(12 / 17)$ by 16 weeks, and $92 \%(12 / 13)$ by 20 weeks. One mother continued using a shield for every breastfeed at 20 weeks due to persistent nipple pain.

\section{Discussion}

For mothers experiencing pain, use of a shield did not reduce the volume of milk transferred during breastfeeding and did not impact the degree of breast emptying (PAMR) (Table 2). ${ }^{22}$ Our findings suggest that shield use in PG did not inhibit the stimulation of neural impulses through suckling and subsequent milk ejection or milk removal. In contrast, shield use in the CG resulted in reduced PAMR and volume (Fig. 1). It is recognized that adequate intraoral vacuum is the primary mechanism of milk removal from the breast. ${ }^{23}$ Therefore, it is possible that for successfully breastfeeding infants with limited or no prior exposure to a shield, introduction of a shield for a single monitored
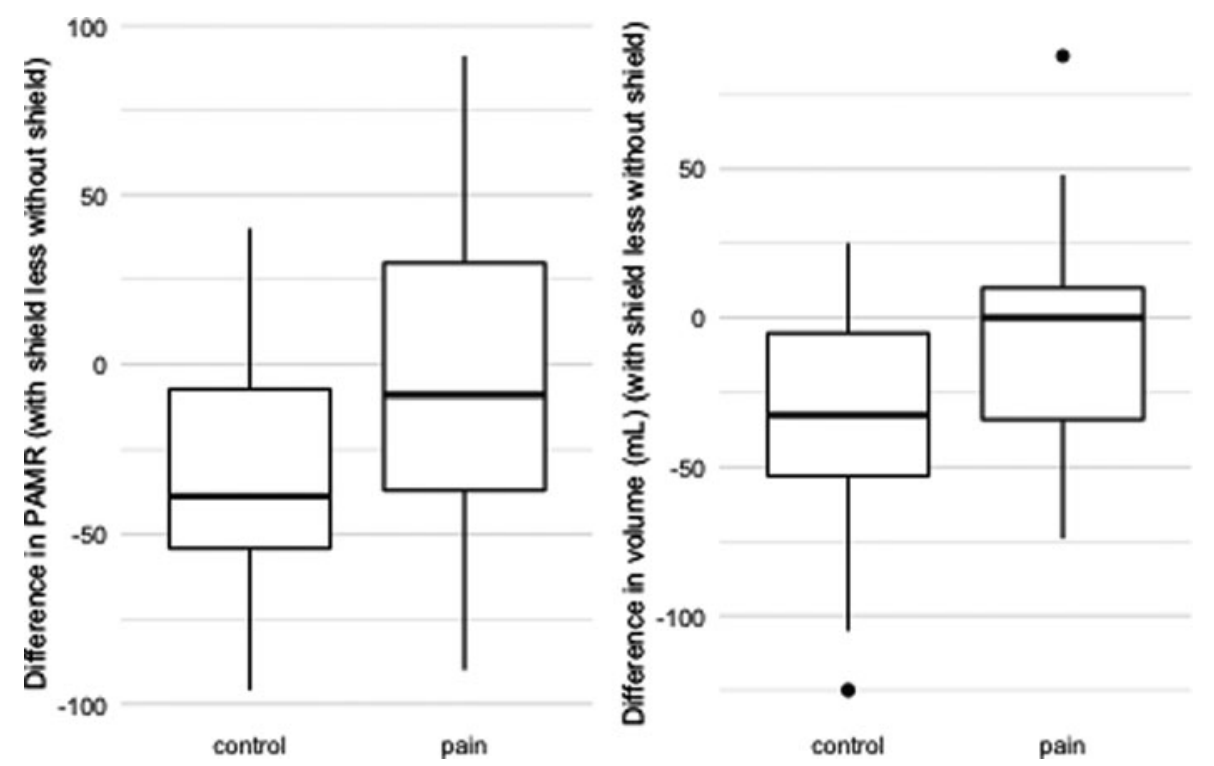

FIG. 1. PAMR and volume for breastfeeds with and without shield use. PAMR, percentage of available milk removed. 
Table 3. Twenty-Four Hour Milk Profile Characteristics of Pain and Control Groups

\begin{tabular}{|c|c|c|c|}
\hline & $\begin{array}{c}\text { Pain } \\
\text { group } \\
(\mathrm{n}=25)\end{array}$ & $\begin{array}{c}\text { Control } \\
\text { group } \\
(\mathrm{n}=34)\end{array}$ & p-Value \\
\hline $\begin{array}{l}\text { Breastfeeding } \\
\text { frequency/24 hours }\end{array}$ & $11 \pm 3$ & $12 \pm 3$ & 0.17 \\
\hline $\begin{array}{l}\text { Breastfeed duration left } \\
\text { (minutes) }\end{array}$ & $19 \pm 7$ & $14 \pm 5$ & 0.002 \\
\hline $\begin{array}{l}\text { Breastfeed duration } \\
\text { right (minutes) }\end{array}$ & $18 \pm 7$ & $14 \pm 6$ & 0.008 \\
\hline $\begin{array}{l}\text { Infant milk intake at } \\
\text { breast (mL/24 hours) }\end{array}$ & $526 \pm 180$ & $731 \pm 207$ & $<0.001$ \\
\hline $\begin{array}{l}\text { Infant total milk intake } \\
\text { (breastfeeds and } \\
\text { supplementary feeds, } \\
\text { mL/24 hours) }\end{array}$ & $894 \pm 268$ & $830 \pm 174$ & 0.30 \\
\hline $\begin{array}{l}\text { Mothers pumping and } \\
\text { breastfeeding }\end{array}$ & $14(56)$ & $9(26)$ & 0.04 \\
\hline $\begin{array}{l}\text { Pumping frequency/24 } \\
\text { hours }\end{array}$ & $4 \pm 3$ & $1 \pm 1$ & 0.005 \\
\hline $\begin{array}{l}\text { Volume pumped } \\
\text { (mL/24 hours) }\end{array}$ & $286 \pm 219$ & $164 \pm 169$ & 0.15 \\
\hline $\begin{array}{l}\text { Total milk production } \\
\text { (mL/24 hours) }\end{array}$ & $730 \pm 221$ & $813 \pm 169$ & 0.13 \\
\hline PAMR left breast (\%) & $63 \pm 16$ & $66 \pm 14$ & 0.53 \\
\hline PAMR right breast (\%) & $63 \pm 14$ & $64 \pm 16$ & 0.79 \\
\hline
\end{tabular}

All results are reported in mean \pm SD except for mothers pumping and breastfeeding: $n(\%)$.

$\mathrm{SD}$, standard deviation.

breastfeed may alter intraoral vacuum pressure and/or nutritive sucking patterns resulting in reduced milk transfer. Woolridge et al. ${ }^{7}$ found altered sucking patterns in newborn infants with use of the Mexican hat shield. Further investigation is required to determine the impact of shield use on infant sucking dynamics in both women experiencing pain and those using shields for other reasons.
Our finding of similar milk transfer volumes in PG dyads with and without ultrathin silicone shield use is consistent with the findings of Woolridge et al. ${ }^{7}$ where no difference in milk transfer volumes was observed with thin latex shield use. In contrast, reduced milk transfer was observed with use of the rubber "Mexican Hat" shield, ${ }^{7}$ and Auerbach et al. ${ }^{8}$ reported a reduction in pumped volume with use of a silicone shield. It is possible that the thick rubber structure of the "Mexican hat" shield inhibited triggering of the milk ejection reflex and/or altered infant sucking dynamics, thereby resulting in reduced milk removal. Alternatively a much stronger intraoral vacuum may be required to remove milk from this particular shield. The researchers' attribution of differences in milk volume to shield use only must be considered with caution as the studies did not account for the degree of fullness of the breast and/or PAMR ${ }^{22}$ and included women in both early and late lactation who did not have an established full milk production.

It was surprising to find that for PG mothers, mean VAS scores were similar with and without shield use. PG mothers reported initiating shield use within the first postnatal week, and most had not attempted breastfeeding without a shield for several weeks before the study. As pain is a transitory sensation that changes in intensity and duration over time,${ }^{24}$ it is possible that the intensity of nipple pain experienced during breastfeeding in the early postnatal period had decreased to lower levels as measured at the time of the study, and so the nipple shield was used for longer than clinically indicated. Clinical assessment of nipple pain is complex and requires a more holistic evaluation, considering its multidimensional and multifactorial causes. ${ }^{25}$ While the nipple shield may provide initial relief from mechanical trauma, recent evidence suggests that mothers can be equipped with knowledge and skills to successfully achieve self-management of pain. ${ }^{26}$ For mothers that initiate shield use to manage nipple pain, education and follow-up to support weaning from the nipple shield may be helpful.

Table 4. Infant Feeding Milk Type and Method for Pain Group and Control Group at 12, 16, and 20 WeEks Postnatal

\begin{tabular}{|c|c|c|c|c|c|c|}
\hline & \multicolumn{2}{|c|}{ Breastfeeding and bottle feeding } & \multicolumn{2}{|c|}{ Breastfeeding only } & \multicolumn{2}{|c|}{ Bottle feeding only } \\
\hline & $P G$ & $C G$ & $P G$ & $C G$ & $P G$ & $C G$ \\
\hline \multicolumn{7}{|c|}{ Week $12(\mathrm{PG} n=23$, CG $n=33)$} \\
\hline Any breast milk & $21(91)$ & $33(100)$ & - & - & - & - \\
\hline Breast milk only & $7(30)$ & $4(12)$ & $7(30)$ & $28(85)$ & $1(4)$ & $0(0)$ \\
\hline Breast milk and formula & $5(22)$ & $1(3)$ & - & - & $1(4)$ & $0(0)$ \\
\hline Formula only & - & - & - & - & $2(9)$ & $0(0)$ \\
\hline \multicolumn{7}{|c|}{ Week 16 (PG $n=20$, CG $n=29)$} \\
\hline Any breast milk & $17(85)$ & $29(100)$ & - & - & - & - \\
\hline Breast milk only & $4(20)$ & $5(17)$ & $7(35)$ & $24(83)$ & $1(5)$ & $0(0)$ \\
\hline Breast milk and formula & $4(20)$ & $0(0)$ & - & - & $1(5)$ & $0(0)$ \\
\hline Formula only & - & - & - & - & $3(15)$ & $0(0)$ \\
\hline \multicolumn{7}{|c|}{ Week $20($ PG $n=17$, CG $n=27)$} \\
\hline Any breast milk & $13(65)$ & $26(96)$ & — & - & - & - \\
\hline Breast milk only & $4(24)$ & 5 (19) & $6(35)$ & $18(67)$ & $0(0)$ & $0(0)$ \\
\hline Breast milk and formula & $3(18)$ & $1(4)$ & - & - & $0(0)$ & $0(0)$ \\
\hline Formula only & - & - & - & - & $4(24)$ & $1(4)$ \\
\hline
\end{tabular}

Data are reported as $n(\%)$.

$\mathrm{CG}$, control group; $\mathrm{PG}$, pain group. 
The most commonly cited reasons for shield use are pain or suboptimal attachment to the breast. ${ }^{27,28}$ In this study, the sensory nature of nipple pain was reflected in the most frequently selected McGill questionnaire descriptors, for example, pinching, tender, stinging, pulling, tingling, sharp, stabbing, and shooting. These indicate physical or mechanical aspects of pain. Indeed, McClellan et al. ${ }^{29}$ showed that for women experiencing pain infants compressed the base of the nipple and applied stronger intraoral vacuums during breastfeeding. Indeed, use of a nipple shield may be an indicator of an underlying breastfeeding issue such as altered sucking dynamics, including atypical infant intraoral vacuum or tongue movement. Reverse causation is possible, whereby nipple shield use is deemed the cause of early weaning, low milk transfer, or other feeding difficulties when in fact there may be preexisting issues that lead to the initiation of nipple shield use.

While the PG's lower rate of breast milk feeding at 20 weeks was not statistically significant, the study was not designed to detect a difference in this secondary outcome. Regardless, the $76 \%$ PG dyads continuing to feed their breast milk at 4 months were similar to the $69 \%$ reported for the Australian population. ${ }^{30}$ Kronborg et al. ${ }^{5}$ reported a threefold risk of earlier cessation of exclusive breastfeeding duration with shield use. Most of our participants had characteristics associated with longer breastfeeding duration that is, older maternal age, highly educated, married ${ }^{31}$ with longer intended breastfeeding duration. ${ }^{32-34}$ However, the PG mothers that weaned before 20 weeks had short intended breastfeeding durations, had stopped using the shield before 12 weeks on average, and cited low milk supply as their reason for weaning. While use of a shield did not impact milk removal and was not a cited reason for weaning, it is possible that reduced feeding and pumping frequency over time contributed to a perceived or actual reduction in milk supply and compounded by the continuing burdens of nipple pain and regular breast expression led to early cessation of breastfeeding.

A proportion of PG mothers had a low milk production despite regular pumping (Table 3 ) and so introduced infant formula and/or weaned before 20 weeks. It has been postulated that use of a nipple shield may downregulate milk production by reducing nipple stimulation during breastfeeding, therefore blunting the prolactin response to suckling. To investigate this, Amatayakul et al. $^{35}$ examined intraindividual differences in maternal serum prolactin and cortisol concentrations and transfer volumes for breastfeeds with and without use of an ultrathin silicone nipple shield at 8 days postpartum. While milk transfer volumes were lower with nipple shield use, there were no differences in baseline and serial postfeed prolactin concentrations. There is evidence that prolactin has an important role in allowing lactation to occur, rather than in short or longer-term regulation of milk synthesis. ${ }^{36-41}$ In this study low milk production was observed in one-third of mothers that had consistently used a nipple shield from the first postnatal week-if nipple shield use was to impact neurophysiological pathways of milk removal or production, it would be observed across a greater proportion of PG mothers.

The finding of low milk supply in one-third of PG mothers highlights the complexity of breastfeeding problems. While shield use has been associated with shorter exclusive breastfeeding duration in mothers with concurrent problems such as poor attachment, mastitis, and perceived low milk supply, ${ }^{42,43}$ it may be that the shield per se is not the issue but rather the interplay of coexisting factors that impacts breastfeeding exclusivity and duration. Several extrinsic and intrinsic factors are known to impact milk production and were not accounted for in this study, as the focus was on milk transfer rather than production. Extrinsic factors such as breastfeeding and pumping frequency in the early postpartum period are associated with subsequent milk production. ${ }^{44,45} \mathrm{It}$ is possible that mothers with nipple pain in the early postnatal period may limit breastfeeding duration and/or frequency to avoid pain, thereby limiting milk removal and subsequent 24 hour production volume. While knowledge of intrinsic factors such as endocrine and genetic factors is emerging in human lactation, animal model studies show that a complex interplay of hormones such as insulin and thyroid and growth hormone are required to support milk production, while zinc transporter gene mutations and altered cell signaling pathways impact mammary gland development and milk secretion. ${ }^{46}$

Indeed, most mothers in our study weaned from the shield by 12 weeks due to a resolution of nipple pain, concurring with evidence that mothers found that shield use facilitated the initiation and continuation of breastfeeding up to 20 weeks and/or prevented early weaning. ${ }^{4,27,47}$ Mothers with breastfeeding difficulties, including pain and perceived low milk production, require careful assessment, a tailored breastfeeding plan, and close follow-up.

In our study, CG infants with novel exposure to a nipple shield had significantly lower milk transfer as measured by both volume and PAMR. A further nine infants from CG refused to attach to the breast with a shield $(n=8)$ or intraoral vacuum tubing $(n=1)$ in situ, suggesting a preference for the bare nipple. The human buccal mucosa, palatine ridges, and tongue are rich in Merkel cells. ${ }^{48}$ These mechanoreceptors of tactile stimuli communicate sensory information regarding the shape, edges, and curvatures of objects presented to the mouth and mediate human behavior imprinting from 35 weeks gestation. ${ }^{49,50}$ Innervation of the mouth, as represented in Penfield's sensory homunculus, indicates considerable somatosensory input from the mouth to a large area of the cerebral cortex. ${ }^{50}$ It is possible that the introduction of foreign intraoral objects that differ from the maternal breast (such as shields, bottle teats, and supplemental nursing system tubing) beyond the early imprinting time of the perinatal period may result in refusal or altered sucking dynamics resulting in reduced milk transfer in the exclusively breastfed infant.

Nipple shield use was associated with lower milk transfer rates for both PG and CG dyads, which did not impact transfer volume or PAMR. Feed durations were also on average 2-3 minutes longer, although this difference was not statistically significant. Further examination with an adequately powered study is required to determine whether infants feed for longer durations when using a nipple shield to obtain the required feed volume.

A limitation of this study is that we were only able to obtain usable data for 25 breastfeeding dyads using a shield to manage nipple pain, rather than the 30 dyads required to achieve a study power of $>0.80$. Therefore, study findings should be interpreted with caution.

While we cannot extrapolate an infant's response to the first exposure to a shield beyond the perinatal period, it is worth considering the potential impact of reduced breast 
emptying and milk transfer when a shield is used for reasons other than pain such as flat or inverted nipples,${ }^{27}$ disorganized suck, ${ }^{47}$ prematurity, and hypotonicity. ${ }^{6}$ In this study nipple shields were introduced to healthy breastfeeding dyads at one study visit for research purposes only. Initiation of nipple shield use should only be considered for dyads with specific needs and access to lactation support. There are advantages and disadvantages associated with shield use, ${ }^{51}$ and monitoring of adequate breast emptying and infant milk intake during shield use is recommended. Furthermore, clinical guidelines are needed to direct the use of shields and strategies for weaning from the shield.

\section{Conclusion}

Findings from this study suggest that in mothers using an ultrathin silicone nipple shield for pain, adequate breast emptying is achieved, with no impact of shield use on milk transfer as measured by milk volume and percent available milk removed. Nipple pain was not diminished with shield use when assessed several weeks after commencing use. Most mothers that initiated shield use in the first postnatal week had stopped using the shield by 16 weeks postnatal and continued breastfeeding to 20 weeks, suggesting that shield use may have contributed to the continuation of breastfeeding.

\section{Acknowledgments}

The authors acknowledge all the mothers and infants for their participation.

\section{Disclosure Statement}

The authors declare that they have no competing interests. V.S.C. received a scholarship from Science without Borders, Government of Brazil. S.L.P., D.T.G., and C.T.L. receive salaries from an unrestricted research grant paid by Medela AG to The University of Western Australia. The funding bodies were not involved in the study design, collection, analysis, and interpretation of data, writing of the article, and the decision to submit the article for publication.

\section{AU3 Funding Information}

\section{References}

1. Forster DA, McLachlan HL. Breastfeeding initiation and birth setting practices: A review of the literature. J Midwifery Womens Health 2007;52:273-280.

2. World Health Organization. Expert consultation on the optimal duration of exclusive breastfeeding. Available at https:// who.int/nutrition/topics/infantfeeding_recommendation/en/ (accessed June 11, 2019).

3. Schwartz K, D'Arcy HJ, Gillespie B, et al. Factors associated with weaning in the first 3 months postpartum. $J$ Fam Pract 2002;51:439-444.

4. Hanna S, Wilson M, Norwood S. A description of breastfeeding outcomes among U.S. mothers using nipple shields. Midwifery 2013;29:616-621.

5. Kronborg H, Foverskov E, Nilsson I, et al. Why do mothers use nipple shields and how does this influence duration of exclusive breastfeeding? Matern Child Nutr 2017;13: e12251.
6. Eglash A, Ziemer AL, Chevalier A. Health professionals' attitudes and use of nipple shields for breastfeeding women. Breastfeed Med 2010;5:147-151.

7. Woolridge MW, Baum JD, Drewett RF. Effect of a traditional and of a new nipple shield on sucking patterns and milk flow. Early Hum Dev1980;4:357-364.

8. Auerbach KG. The effect of nipple shields on maternal milk volume. J Obstet Gynecol Neonatal Nurs 1990;19: 419-427.

9. Meier PP, Brown LP, Hurst NM, et al. Nipple shields for preterm infants: Effect on milk transfer and duration of breastfeeding. J Hum Lact 2000;16:106-114; quiz 129131.

10. Daly SE, Kent JC, Owens RA, et al. Frequency and degree of milk removal and the short-term control of human milk synthesis. Exp Physiol 1996;81:861-875.

11. Daly SE, Di Rosso A, Owens RA, et al. Degree of breast emptying explains changes in the fat content, but not fatty acid composition, of human milk. Exp Physiol 1993;78: 741-755.

12. McClellan HL, Sakalidis VS, Hepworth AR, et al. Validation of nipple diameter and tongue movement measurements with B-mode ultrasound during breastfeeding. Ultrasound Med Biol 2010;36:1797-1807.

13. Arthur PG, Hartmann PE, Smith M. Measurement of the milk intake of breast-fed infants. $J$ Pediatr Gastroenterol Nutr 1987;6:758-763.

14. Huskisson EC. Measurement of pain. Lancet 1974;2:11271131.

15. Bijur PE, Silver W, Gallagher EJ. Reliability of the visual analog scale for measurement of acute pain. Acad Emerg Med 2001;8:1153-1157.

16. Melzack R. The McGill Pain Questionnaire: Major properties and scoring methods. Pain 1975;1:277-299.

17. Kent JC, Mitoulas LR, Cregan MD, et al. Volume and frequency of breastfeedings and fat content of breast milk throughout the day. Pediatrics 2006;117:e387-e395.

18. Casey CE, Hambidge KM, Neville MC. Studies in human lactation: Zinc, copper, manganese and chromium in human milk in the first month of lactation. Am J Clin Nutr 1985;41:1193-1200.

19. Kent JC, Ramsay DT, Doherty D, et al. Response of breasts to different stimulation patterns of an electric breast pump. J Hum Lact 2003;19:179-186; quiz 187-188, 218.

20. McClellan HL, Hepworth AR, Kent JC, et al. Breastfeeding frequency, milk volume, and duration in mother-infant dyads with persistent nipple pain. Breastfeed Med 2012;7: 275-281.

21. Hui LL, Schooling CM, Leung SS, et al. Birth weight, infant growth, and childhood body mass index: Hong Kong's children of 1997 birth cohort. Arch Pediatr Adolesc Med 2008;162:212-218.

22. Kent JC, Mitoulas L, Cox DB, et al. Breast volume and milk production during extended lactation in women. $\operatorname{Exp}$ Physiol 1999;84:435-447.

23. Geddes DT, Kent JC, Mitoulas LR, et al. Tongue movement and intra-oral vacuum in breastfeeding infants. Early Hum Dev 2008;84:471-477.

24. Marchand S. The physiology of pain mechanisms: From the periphery to the brain. Rheum Dis Clin North Am 2008;34: 285-309.

25. Amir LH, Jones LE, Buck ML. Nipple pain associated with breastfeeding: Incorporating current neurophysiology into clinical reasoning. Aust Fam Physician 2015;44:127-132. 
26. Lucas R, Zhang Y, Walsh SJ, et al. Efficacy of a breastfeeding pain self-management intervention: A pilot randomized controlled trial. Nurs Res 2019;68:E1-E10.

27. Powers D, Tapia VB. Women's experiences using a nipple shield. J Hum Lact 2004;20:327-334.

28. Brigham M. Mothers' reports of the outcome of nipple shield use. J Hum Lact 1996;12:291-297.

29. McClellan H, Geddes D, Kent J, et al. Infants of mothers with persistent nipple pain exert strong sucking vacuums. Acta Paediatr 2008;97:1205-1209.

30. Australian Institute of Health and Welfare. 2010 Australian National Infant Feeding Survey: Indicator Results. Camberra, Australia: Australian Government, 2011.

31. Ajetunmobi $\mathrm{O}$, Whyte $\mathrm{B}$, Chalmers $\mathrm{J}$, et al. Informing the 'early years' agenda in Scotland: Understanding infant feeding patterns using linked datasets. $J$ Epidemiol Community Health 2014;68:83-92.

32. O'Brien M, Buikstra E, Hegney D. The influence of psychological factors on breastfeeding duration. $J$ Adv Nurs 2008;63:397-408.

33. Meedya S, Fahy K, Kable A. Factors that positively influence breastfeeding duration to 6 months: A literature review. Women Birth 2010;23:135-145.

34. Thulier D, Mercer J. Variables associated with breastfeeding duration. J Obstet Gynecol Neonatal Nurs 2009;38: 259-268.

35. Amatayakul K, Vutyavanich T, Tanthayaphinant O, et al. Serum prolactin and cortisol levels after suckling for varying periods of time and the effect of a nipple shield. Acta Obstet Gynecol Scand 1987;66:47-51.

36. Cregan MD, Hartmann PE. Computerized breast measurement from conception to weaning: Clinical implications. J Hum Lact 1999;15:89-96.

37. Bohnet HG, Kato K. Prolactin secretion during pregnancy and puerperium: Response to metoclopramide and interactions with placental hormones. Obstet Gynecol 1985;65: 789-792.

38. Chatterton RT, Jr., Hill PD, Aldag JC, et al. Relation of plasma oxytocin and prolactin concentrations to milk production in mothers of preterm infants: Influence of stress. J Clin Endocrinol Metab 2000;85:3661-3668.

39. Cox DB, Owens RA, Hartmann PE. Blood and milk prolactin and the rate of milk synthesis in women. Exp Physiol 1996;81:1007-1020.

40. Howie PW, McNeilly AS, McArdle T, et al. The relationship between suckling-induced prolactin response and lactogenesis. J Clin Endocrinol Metab 1980;50:670-673.
41. McNeilly AS, Robinson IC, Houston MJ, et al. Release of oxytocin and prolactin in response to suckling. $\mathrm{Br}$ Med J (Clin Res Ed) 1983;286:257-259.

42. Chapman DJ, Perez-Escamilla R. Does delayed perception of the onset of lactation shorten breastfeeding duration? $J$ Hum Lact 1999;15:107-111.

43. Scott JA, Binns CW, Oddy WH. Predictors of delayed onset of lactation. Matern Child Nutr 2007;3:186-193.

44. Yamauchi Y, Yamanouchi I. Breast-feeding frequency during the first 24 hours after birth in full-term neonates. Pediatrics 1990;86:171-175.

45. De Carvalho M, Robertson S, Friedman A, et al. Effect of frequent breast-feeding on early milk production and infant weight gain. Pediatrics 1983;72:307-311.

46. Lee S, Kelleher SL. Biological underpinnings of breastfeeding challenges: The role of genetics, diet, and environment on lactation physiology. Am J Physiol Endocrinol Metab 2016;311:E405-E422.

47. Chertok IR. Reexamination of ultra-thin nipple shield use, infant growth and maternal satisfaction. J Clin Nurs 2009; 18:2949-2955.

48. Haeberle H, Lumpkin EA. Merkel cells in somatosensation. Chemosens Percept 2008;1:110-118.

49. Lipchock SV, Reed DR, Mennella JA. The gustatory and olfactory systems during infancy: Implications for development of feeding behaviors in the high-risk neonate. Clin Perinatol 2011;38:627-641.

50. Mobbs EJ, Mobbs GA, Mobbs AE. Imprinting, latchment and displacement: A mini review of early instinctual behaviour in newborn infants influencing breastfeeding success. Acta Paediatr 2016;105:24-30.

51. Chow S, Chow R, Popovic M, et al. The use of nipple shields: A review. Front Public Health 2015;3:236.

Address correspondence to:

S. Lisa Perrella, PhD

Faculty of Science

School of Molecular Sciences

The University of Western Australia M310, 35 Stirling Highway

Crawley, WA 6009

Australia

E-mail: sharon.perrella@uwa.edu.au 


\section{AUTHOR QUERY FOR BFM-2020-0110-VER9-COENTRO_1P}

AU1: Please identify (highlight or circle) all authors' surnames for accurate indexing citations.

AU2: Include IRB approval or waiver statement in the Materials and Methods section. The Clinical Trial Registration number, if applicable, should be included at the end of the abstract.

AU3: Please provide funding information. Include the full name (no abbreviations) of funding agency(ies)/institution(s) and grant numbers. Ensure the accuracy of this information. If no funding was received, please clearly state as such. 